\title{
EDITORIAL
}

\section{Life, Liberty, and the Pursuit of Quality?}

The word "quality" seems to be thrown around quite a bit in medicine these days. We have continuous quality improvement, quality initiatives, quality projects. In our hospital, we now have a quality officer, quality department, and many, many quality improvement projects. I've become suspicious of anything with the word "quality" in the title. Using the "quality" designation to legitimize your organization is more or less like telling everyone you're an expert without actually having to prove it. It is not much different than false advertising. Who doesn't want quality? It is synonymous with care, dedication, and desire to improve. Nobody is going to stand up and say, "Excellence really isn't important, let's just strive to be average." On the other hand, most organizations are average. And since the pursuit of quality is endless... it is more or less like a death march.

Has medicine really been that bad for all these years? Is it from a lack of effort? And does anyone really think our quality improvement projects will solve this epidemic of inadequacy? To incentivize quality, my hospital just hosted its third annual quality fair where departments throughout the medical center displayed their quality improvement projects. The winner received nice ribbons and hospital recognition for quality health care. These projects are supposed to be continuous but in reality, in my IR section, some are more like Lent without the fun of Mardi Gras. Although we don't fast and still eat meat on Fridays, for part of the year, the whole section does a little extra work and makes small sacrifices to further "quality" care. This year, my VIR section displayed our results in locating, contacting, and begging patients to come back to have their optional filters removed (we're above $70 \%$ these days-www.filterlaw.com is based in Chicago-this project will be continuous). In past years, we did projects involving rounding, radiation protection, and consultations. We've never won. I'm not sure that we've ever come close, although I think all of our projects were excellent and meritorious.

The other side of quality is the punitive aspects of failing. One example of this involves the so-called never events, created by (guess who) the National Quality Forum. Of course, these events were not grounded in evidence-based medicine (sound familiar?). Again, we have a few people probably sitting on a porch somewhere deciding that this or that should never occur. I don't like the words never or always - they should be eliminated from both multiple choice tests and medicine. To me (and probably anyone else), "never event" implies that these are things so egregious that they should never happen and are always preventable. When they occur, it indicates that someone really screwed up; healthcare ala boneheads. When I first read the list, I was surprised that several of the events actually made sense, like, "artificial insemination of wrong sperm or egg." OK, I can understand how that one could be a problem and difficult to explain. I don't know how often it happens but never is probably reasonable. On the other hand, when I got to "vascular catheter-associated infection" my eyes bugged out of my head. Anyone who believes that every catheter infection is preventable and analogous to artificially inseminating the wrong sperm or egg is out of their mind. If you think every catheter infection is caused by incompetence, you really don't understand the subject. There are 80,000 line infections in the USA per year. Clearly, a percentage of these are caused by health care workers (and these need to be eliminated), but there is no way every single one of them is preventable. I once had a patient who had repeated port infections-each one essentially a "never event." I couldn't figure it out. Risk Management was involved, our medical legal team was on the case, and special care was given to this patient. She had a particularly demanding family who threatened everyone involved with lawsuits. Eventually, someone outside the family noticed the patient accessing her own port and surreptitiously injecting it with dirt and Kool-Aid. Welcome to my life. Despite what the National Quality Forum thinks, I decided that these "never events" probably weren't my fault. In my view, calling catheter-related infections "never events" is only accurate in that preventing all of them could "never" occur...except maybe in Nevernever Land.

\footnotetext{
${ }^{1}$ Section of Vascular and Interventional Radiology, University of Chicago Medical Center, Chicago, Illinois.

Address for correspondence and reprint requests: Brian Funaki, M.D., Professor and Section Chief, Section of Vascular and Interventional Radiology, University of Chicago Medical Center, 5840 S. Maryland Avenue, MC 2026, Chicago, IL60637 (e-mail: bfunaki@ radiology.bsd.uchicago.edu).
}

Complications in Interventional Oncology; Guest Editor, Robert J. Lewandowski, M.D.

Semin Intervent Radiol 2011;28:131-132. Copyright (C) 2011 by Thieme Medical Publishers, Inc., 333 Seventh Avenue, New York, NY 10001, USA. Tel: $+1(212)$ 584-4662.

DOI: http://dx.doi.org/10.1055/s-0031-1280649.

ISSN 0739-9529. 
The pursuit of quality is interesting in and of itself, particularly in popular media. Nearly every day, I see a story in the news about how we have the most expensive health care in the United States, but we don't have quality health care. I guess that could be true but I personally don't know anyone who has left the United States to go elsewhere for their health care. (I take that back, actually I did help to treat a patient once who went abroad for a gastric bypass and ended up needing a small bowel transplant.) If you look at other countries, many have the same issues that we do-when researching this editorial, I googled "Quality Health Care" and got back $\sim 222$ million results. One headline read, "Thousands dying from preventable hospital errors." It was an article about Australian health care. Perhaps people in some countries are healthier because they actually take care of themselves. Have you ever traveled in Europe and seen a pack of fat people? They are invariably American tourists. One comparison often made to demonstrate failure in health care is air travel, which is purported to be "equally complex" to medicine for which "failure is also a life-and-death matter." Really? Are there experts walking around saying, "Now there's an industry that medicine should try to emulate, air travel. Nothing ever goes wrong there and travelers are always so happy and satisfied in airports." The problem with this comparison is that before airplanes take off, they can either be fixed or junked. We can't do the same with people. If my patients were planes, not only would I not fly, I'd live underground to avoid being crushed by all the planes crashing everywhere.

Like life, health care is not perfect-it never will be either. That doesn't mean we should stop trying to enhance it, but it does mean that we need to take a realistic look at what we have, ask ourselves why we are where we are, and come up with some reasonable ways to get better. And in my opinion, we really don't need to use the word "quality" every time we do this.

Brian Funaki, M.D. ${ }^{1}$ Editor-in-Chief 